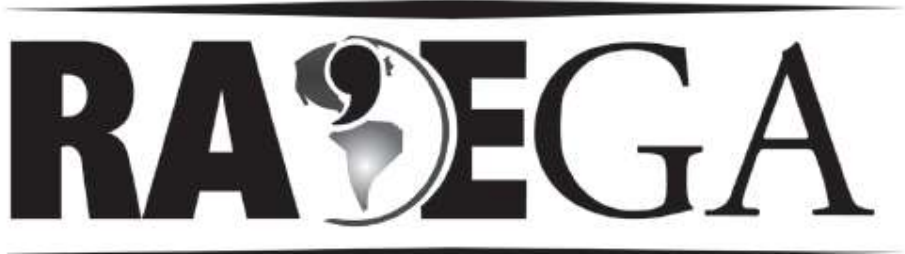

O ESPAÇO GEOGRÁFICO EM ANÁLISE

\title{
INDICAÇÃO PARA O USO DA TERRA NA BACIA HIDROGRÁFICA DO RIO SALOBRA - SERRA DA BODOQUENA, MATO GROSSO DO SUL'.
}

\section{INDICATION FOR THE LAND USE OF THE WATERSHED IN SALOBRA RIVER - BODOQUENA PLATEAU, MATO GROSSO DO SUL STATE.}

\author{
João Cândido André da SILVA NETO²
}

\section{RESUMO}

O processo de apropriação da natureza na Bacia Hidrográfica do Rio Salobra tem ocorrido muitas vezes de maneira intensa e em áreas inadequadas, não respeitando as características físico-naturais das paisagens. Esse processo deveria apoiar-se na capacidade de exploração econômica dos recursos naturais e na resiliência desse ecossistema. Nessa perspectiva, objetivou-se mapear as áreas adequadas para cada tipo de uso da terra, conforme as características da paisagem, verificando-se que $64 \%$ da área estudada apresentam problemas de conservação dos solos ou são indicadas para reflorestamento e, $36 \%$ da área são indicadas para uso com pastagem ou para agricultura com lavouras de ciclos curtos/ sazonais.

Palavras-chave: Uso da terra; Apropriação da Natureza; Sistema de Informações Geográficas.

\section{ABSTRACT}

The process of appropriation of nature in the Watershed of Salobra River has occurred many times so intense and in inappropriate areas, not respecting the physical and natural characteristics of this landscape. This process should be

\footnotetext{
1 Parte do relatório de qualificação de doutoramento do autor, apresentada ao Programa de Pósgraduação em Geografia pela Universidade Estadual Paulista- UNESP- Campus de Presidente Prudente. ${ }^{2}$ Aluno de doutorado do Programa de Pós-graduação em Geografia pela Universidade Estadual PaulistaUNESP- Campus de Presidente Prudente, Bolsista pelo CNPQ. Presidente Prudente, SP, Brasil. joaokandido@yahoo.com.br
} 
based on the capability of economic exploitation of natural resources and the resilience of this ecosystem. From this perspective, the objective was to map appropriate areas for each type of land use, according characteristics of the landscape, verifying that $64 \%$ of the study area have problems of soil conservation or are indicated for reforestation, and $36 \%$ of the area are indicated for use with pasture or farming crops of short cycles/seasonal.

Keywords: Land use; Appropriation of the Nature; Geographic Information System.

\section{INTRODUÇÃO}

O homem tem-se preocupado com a erosão dos solos desde que passou a desenvolver a agricultura, quando adquiriu um modo de vida fixo intensificando o uso do solo, consequentemente levando a destruição da cobertura vegetal acarretando a exposição do solo aos processos erosivos (BERTONI \& LOMBARDI NETO, 1999).

A intensificação dos processos erosivos está frequentemente associada aos usos inadequados da terra, que normalmente ocorrer sem 0 conhecimento prévio da área utilizada. Nesse processo de apropriação da natureza, qualquer área pode ser explorada, desrespeitando assim, os limitantes físico-naturais das paisagens.

Justifica-se o presente estudo, por abordar uma área cuja paisagem caracteriza-se por apresentar uma configuração vulnerável, no qual alguns tipos de usos da terra podem desencadear processo de degradação dessa paisagem. Outro ponto ressaltado é o fato de que parte da área da Bacia Hidrográfica do Rio Salobra está inserida no Parque Nacional da Serra da Bodoquena, primeira unidade de conservação de proteção integral federal implantada no Estado de Mato Grosso do Sul, no qual há intenção da criação de um Geopark Bodoquena e Pantanal, conforme proposta apresentada à UNESCO, no Dossiê de candidatura à rede global de Geoparks Nacionais (ESTADO DO MATO GROSSO DO SUL, 2010).

Uma porção significativa da bacia hidrográfica do rio Salobra é caracterizada como um ambiente vulnerável de acordo com suas características físico-ambientais, no qual há uma grande carência de informações que possibilitem um diagnóstico cuidadoso, que permita fazer as 
devidas restrições e indicações de usos adequados para a área (SILVA NETO e NUNES, 2011).

Desse modo, faz-se necessário se verificar quais as limitações quanto aos usos da terra que podem alterar o equilíbrio dinâmico das características naturais da paisagem e comprometer o sistema ambiental.

Assim, é necessário conhecer melhor a dinâmica e limitações dessa área, para se estabelecer diretrizes que subsidiem a utilização, manejo, medidas conservacionistas dos recursos naturais e adoção de restrições mais seguras quanto ao uso do solo.

O presente estudo objetivou indicar os tipos adequados de usos da terra de acordo com as características naturais, antrópicas como uso atual da terra e aptidão agrícola dos solos na bacia hidrográfica do Rio Salobra, visando ainda subsidiar as diretrizes e recomendações para o ordenamento do território.

\section{CARACTERIZAÇÃO DA ÁREA DE ESTUDO}

O presente estudo abordou a Bacia Hidrográfica do Rio Salobra que está localizada na região Sudoeste do estado de Mato Grosso do Sul, considerada uma importante área fonte dos fluxos de matéria e energia da bacia do rio Miranda no Pantanal sul-mato-grossense.

A Bacia Hidrográfica do Rio Salobra tem sua localização compreendida entre as latitudes $20^{\circ} 59^{\prime} 55^{\prime \prime}$ e $20^{\circ}$ 08' $54^{\prime \prime} \mathrm{S}$ e longitudes $57^{\circ} 00^{\prime} 00^{\prime \prime}$ e $56^{\circ}$ 26' 30" W. Sua área estende-se pelos municípios de Bonito (algumas nascentes), Bodoquena (maior parte da extensão de sua rede de drenagem) e Miranda (baixo curso e foz), com área de aproximadamente 2.350 km² (Figura $1)$.

A Bacia Hidrográfica do Rio Salobra caracteriza-se como um ambiente vulnerável no tocante dos aspectos físicos naturais. Assim, faz-se necessário verificar quais as limitações quanto aos usos da terra, que possam alterar o equilíbrio das características naturais da paisagem e comprometer o sistema ambiental. 


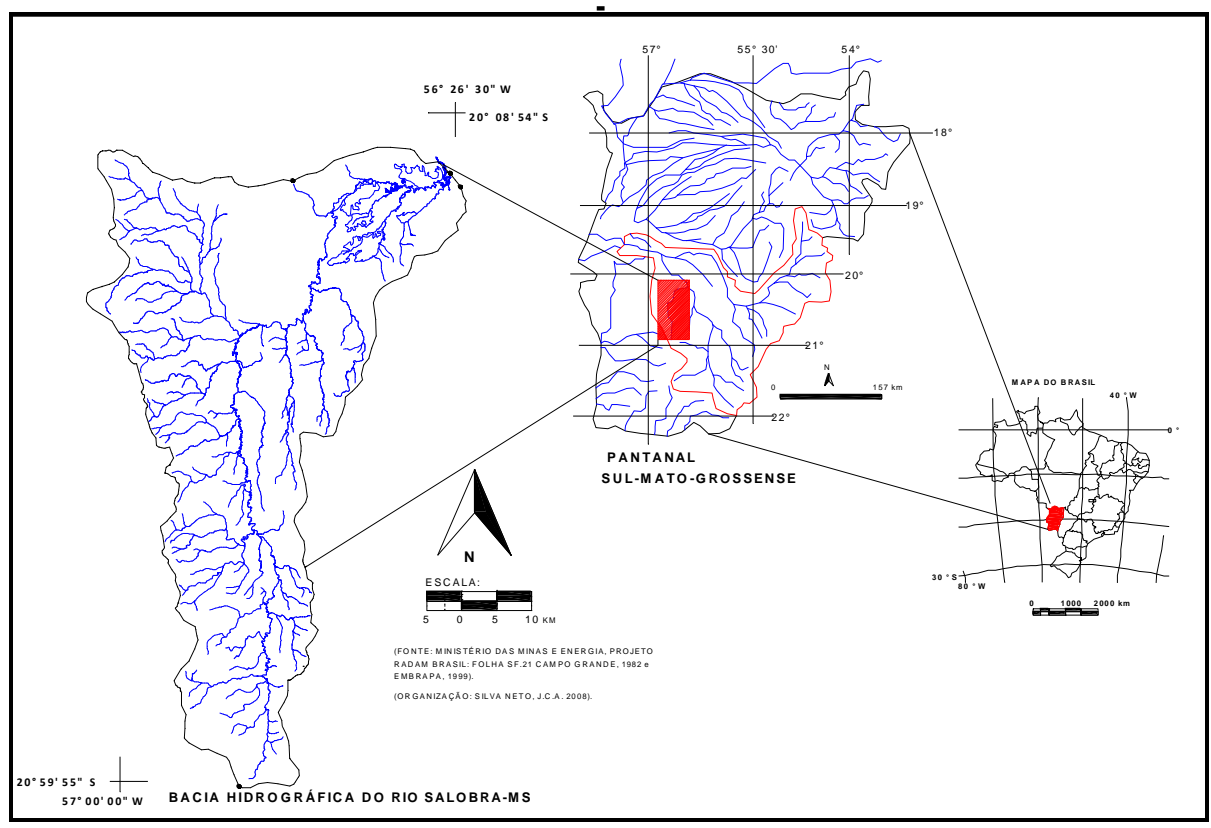

Figura 1- Localização da Bacia Hidrográfica do Rio Salobra-MS.

\section{Formações Geológicas}

Segundo estudo apresentado no projeto RADAMBRASIL (1982) e no relatório de Geologia e Recursos Minerais do Estado de Mato Grosso do Sul (2006), a área da Bacia Hidrográfica do Rio Salobra, apresenta-se estruturada litológicamente sobre o arcabouço geológico da Formação Cerradinho e Formação Bocaína, com rochas do Pré-cambriano Superior e Formação Pantanal do período Quaternário. Apresenta também a ocorrência de rochas do Grupo Cuiabá, Formação Puga e Complexo Rio Apa (Tabela 1).

Tabela 1: Vulnerabilidade Geológica da Bacia Hidrográfica do Rio Salobra. (Base cartográfica: Mapa geológico do Estado do Mato Grosso do Sul, 2006).

\begin{tabular}{|l|l|l|l|}
\hline \multicolumn{1}{|c|}{ Formações } & \multicolumn{1}{|c|}{$\begin{array}{c}\text { Ǵndice de } \\
\text { Vulnerabilidade }\end{array}$} & \multicolumn{1}{c|}{$\begin{array}{c}\text { Grau de } \\
\text { Vulnerabilidade }\end{array}$} & \multicolumn{1}{c|}{$\begin{array}{c}\text { Área } \\
\mathbf{k m}^{\mathbf{2}}\end{array}$} \\
\hline Depósitos aluvionares Q1p2 & 1.00 & Vulnerável & 141.862 \\
\hline Terraços aluvionares Q1p1 & 1.00 & Vulnerável & 336.805 \\
\hline Formação Bocaina Npbo (d) (c) & 0.96 & Vulnerável & 773.266 \\
\hline Formação Puga NPpu & 0.90 & Vulnerável & 137.486 \\
\hline Formação Cerradinho NP3ce (c) (d) & 0.80 & Moderado Vulnerável & 369.391 \\
\hline Grupo Cuiabá NPcum & 0.76 & Moderado Vulnerável & 178.783 \\
\hline Grupo Cuiabá NPcuxt & 0.66 & Mediano Estável & 14.922 \\
\hline Grupo Cuiabá NPcufl & 0.70 & Mediano Estável & 242.645 \\
\hline Complexo Rio Apa PP3ra & 0.36 & Estável & 228.134 \\
\hline
\end{tabular}


De acordo com as unidades geológicas da bacia hidrográfica do rio Salobra, conforme o grau de coesão da rocha, observa-se que $57 \%$ de sua área é classificada como Vulnerável, 23\% como Moderado Vulnerável, 11\% como Mediano Estável e 9\% como Estável.

\section{Vulnerabilidade do relevo}

A vulnerabilidade do relevo foi elaborada a partir dos dados morfométricos de amplitude altimétrica e declividade do terreno, verificando-se na análise individualizada de cada uma dessas variáveis que grande porção da área da bacia (61\%) corresponde às faixas de declividades que apresentaram o Grau Estável. Quanto à amplitude altimétrica, verificou-se que 52\% da área da bacia apresentou o Grau Vulnerável.

Desse modo, a associação entre as variáveis declividade e amplitude altimétrica permitiu analisar o tema relevo, no qual os Graus de Vulnerabilidade Moderado Estável e Estável representaram 39\% da área total da bacia. Essas categorias caracterizam-se por oferecer condições em que prevalece a pedogênese. Conforme Tricart (1977), os processos mecânicos nesses meios atuam pouco e sempre de modo lento (Tabela 2).

O Grau de Vulnerabilidade: Mediano Estável Vulnerável representou $41 \%$ da área total estudada. Essa categoria morfodinâmica Intermediária é caracterizada pelo equilíbrio entre pedogênese e morfogênese. Essa categoria foi definida por Tricart (1977) como meios intergrades determinado pela interferência permanente de morfogênese e pedogênese.

Tabela 2 - Vulnerabilidade do relevo (Base cartográfica - Dados SRTM).

\begin{tabular}{|l|l|l|l|}
\hline Vulnerabilidade & Área em Km² & Área em \% & Grau de Vulnerabilidade \\
\hline $0.90-1.00$ & 73.135 & 3 & Vulnerável \\
\hline $0.76-0.90$ & 387.953 & 17 & Moderado Vulnerável \\
\hline $0.60-0.76$ & 947.742 & 41 & Mediano Estável Vulnerável \\
\hline $0.46-0.60$ & 216.510 & 9 & Moderado Estável \\
\hline $0.33-0.46$ & 696.081 & 30 & Estável \\
\hline
\end{tabular}

O Grau de Vulnerabilidade: Moderado Vulnerável e Vulnerável representou $20 \%$ da área da Bacia do Rio Salobra. Essas áreas são definidas 
como Instáveis por oferecer condições que prevaleça a morfogênese, de maneira genérica pode caracterizar-se por apresentar condições ecológicas difíceis e suscetíveis aos processos de degradação das paisagens.

\section{Tipos de Solos}

A principal característica pedológica da Bacia Hidrográfica do Rio Salobra é a presença de solos provenientes das formações geológicas citadas anteriormente, onde suas litologias variam desde originadas de calcários, ardósias do pré-cambriano (Grupo Corumbá), até dos sedimentos mais recentes da Formação Pantanal.

Outro contraste é quanto ao relevo onde são encontrados alguns tipos de solos, pois variam desde relevo plano até fortemente dissecado. O tipo de solo de maior expressão com relação a área ocupada na Bacia do Rio Salobra é dos Chernossolos Rêndzicos, característicos das áreas com relevo fortemente acidentado, grande parte destes solos são utilizada para pecuária (Tabela 3).

Tabela 3: Relação dos tipos de solos e índice de vulnerabilidade à perda de solos na bacia hidrográfica do Rio Salobra-MS (Base cartográfica - PROJETO RADAMBRASIL, 1982).

\begin{tabular}{|l|l|c|c|c|}
\hline $\begin{array}{c}\text { Nomenclatura Segundo } \\
\text { Projeto RADAMBRASIL } \\
\text { (1982) }\end{array}$ & $\begin{array}{c}\text { Nomenclatura Segundo } \\
\text { Embrapa (1999) }\end{array}$ & $\begin{array}{c}\text { Área em } \\
\text { km² }\end{array}$ & $\begin{array}{c}\text { Área } \\
\text { em\% }\end{array}$ & $\begin{array}{c}\text { Grau } \\
\text { Vulnerabilidade }\end{array}$ \\
\hline Solonetz Solodizado & Planossolos Nátricos & 127,29 & 6 & $\begin{array}{c}\text { Med. Estável } \\
\text { Vulnerável }\end{array}$ \\
\hline Planossolo Solódico & Planossolos Hidromórficos & 56,20 & 2 & $\begin{array}{c}\text { Med. Estável } \\
\text { Vulnerável }\end{array}$ \\
\hline $\begin{array}{l}\text { Terra Roxa Estrutura/ } \\
\text { Latossólica }\end{array}$ & Nitossolos & 70,30 & 3 & $\begin{array}{c}\text { Med. Estável } \\
\text { Vulnerável }\end{array}$ \\
\hline Brunizem avermelhado & Chernossolos Argilúvicos & 346,72 & 15 & $\begin{array}{c}\text { Med. Estável } \\
\text { Vulnerável }\end{array}$ \\
\hline $\begin{array}{l}\text { Podzólico Vermelho- } \\
\text { Amarelado }\end{array}$ & Luvissolos & 140,27 & 6 & $\begin{array}{c}\text { Med. Estável } \\
\text { Vulnerável }\end{array}$ \\
\hline Glei Pouco Húmico & Gleissolos & 124,70 & 5 & Vulnerável \\
\hline Vertissolos & Vertissolos & 245,46 & 11 & Vulnerável \\
\hline Rendzina & Chernossolos Rêndzicos & 1092,84 & 47 & Vulnerável \\
\hline Litólicos & Neossolos Litólicos & 49,788 & 2 & Vulnerável \\
\hline Regossolo & Neossolos Regolíticos & 69,203 & 3 & Vulnerável \\
\hline
\end{tabular}




\section{Intensidade Pluviométrica}

Segundo Crepani et al. (2004) é importante se avaliar a intensidade pluviométrica, pois representa uma relação direta entre as características de precipitação total (quanto chove) e sua distribuição sazonal (quando chove), resultando em última análise na quantidade de energia potencial disponível para transformar-se em energia cinética.

A intensidade pluviométrica no ano de 2009 caracteriza-se por apresentar pouca variação de classes de 525 à $625 \mathrm{~mm} / \mathrm{mês}$, distribuídas em apenas quatro classes por toda extensão da bacia.

Quanto aos índices de vulnerabilidade, todas as classes apresentam os valores máximos na escala de vulnerabilidade 1,0, denominada Vulnerável, com características favoráveis de um ambiente instável no tocante dos processos erosivos.

\begin{tabular}{|l|l|l|l|}
\hline \multicolumn{4}{|c|}{ Quadro 1: Relação da intensidade pluviométrica aos valores de } \\
vulnerabilidade à perda de solo (Fonte: Dados Hidroweb). \\
\hline *I.P. & **V.P.S. & *I.P. & **V.P.S. \\
\hline 375 a 400 & 0,80 & 525 a 550 & 1,00 \\
\hline 400 a 425 & 0,83 & 550 a 575 & 1,00 \\
\hline 425 a 450 & 0,86 & 575 a 600 & 1,00 \\
\hline 450 a 475 & 0,90 & 600 a 625 & 1,00 \\
\hline 475 a 500 & 0,93 & $>625$ & 1,00 \\
\hline 500 a 525 & 0,96 & & \\
\hline
\end{tabular}

* Intensidade Pluviométrica (mm -mês) = T.P.A/N.D.C.

** Vulnerabilidade à Perda de Solo.

No ano de 2009 a precipitação total anual variou de 1375 à 1700 mm, apresentando chuvas concentradas predominantemente no verão (com 46\%) e primavera (23\%) e o período mais seco no inverno (15\%) e outono (16\% do total anual) (Figura 2). 
Figura 2: Gráfico Precipitação Total Anual em 2009 distribuída por estações do ano (Fonte: elaborado pelo autor).

\section{Uso da terra e cobertura vegetal}

No ano de 2009 verificou-se que $40 \%$ da área total da bacia foi utilizada para o desenvolvimento da pecuária extensiva. Esta atividade consiste na criação de gado em grandes extensões de terras, sem limitações quanto ao pisoteio ou a exploração de novas áreas para pastagem (Tabela 4).

Tabela 4- Classes de uso da terra e cobertura vegetal na bacia hidrográfica do rio Salobra em 2009 (Fonte: elaborado pelo autor).

\begin{tabular}{l|c|c}
\hline \multicolumn{1}{c|}{ CLASSES } & ÁREA KM & ÁREA EM \% \\
\hline Mata & 1.107 .117 & 48 \\
\hline Áreas Úmidas & 10.705 & 0 \\
\hline Pastagem & 931.015 & 40 \\
\hline Lavoura & 221.252 & 10 \\
\hline Solo Exposto & 50.698 & 2 \\
\hline
\end{tabular}

As áreas de pastagem não respeitam áreas com declividades acentuadas, consequentemente intensificando os processos erosivos na área, sofrendo assim uma transição do estágio de erosão laminar para erosões em sulcos, resultado direto do pisoteio do gado.

As áreas de mata/floresta representam a maior extensão de área, ocupando $47 \%$ da bacia hidrográfica. As áreas denominadas lavoura são observadas em $10 \%$ da área, correspondendo aos setores com cultivos predominantemente de arroz, milho e feijão. 


\section{Aptidão Agrícola}

Para Bertoni e Lombardi Neto, (1999) a classificação da capacidade de uso do solo busca estabelecer diretrizes para um aproveitamento mais eficiente da terra.

Assim, as terras produtivas são divididas em três categorias principais, que agrupam oito classes de modo mais detalhado, são elas: A) Terras próprias para todos os usos, inclusive cultivos intensivos; B) Terras impróprias para o cultivo intensivo, mais aptas para pastagens e reflorestamento ou manutenção da vegetação natural; C) Terras impróprias para cultivo, recomendadas para proteção da flora, fauna ou recreação.

Bertoni e Lombardi Neto, (1999) ressaltam que as classes de capacidade de uso são caracterizadas, em termos gerais, apenas do ponto de vista das condições físicas da terra, não se comparando com exatidão uma região para outra, mas sim em princípios gerais das condições fundamentais do solo e suas condições locais.

Para Lepsch (2002) o grau de capacidade de uso irá indicar qual intensidade máxima de cultivo pode ser aplicada a determinado solo, sem que sua estrutura seja comprometida, degradada ou ocorra perda seu nutrientes por efeito da erosão.

Conforme Sánchez (1991) aptidão agrícola indica uma referência de localização e distribuição espacial das alternativas de uso, sendo que elas implicam na maior intensidade de uso admitida pela unidade de mapeamento de terras que está sendo avaliada.

Segundo o Atlas Multirreferêncial do Estado do Mato Grosso do Sul (1990) na Bacia Hidrográfica do Rio Salobra são verificados as seguintes classes de aptidão agrícola (Tabela 5):

$1 \mathrm{ABc}$ - aptidão boa nos níveis $\mathrm{ABC}$, solos com boa reserva de nutrientes, relevo plano ou suave ondulado, textura argilosa, correspondendo a $23 \%$ da área total estudada. Uso indicado para lavoura.

2abc - aptidão regular nos níveis abc, solos com medianas reservas de nutrientes, relevo plano e suave ondulado, textura argilosa ou média, ocupa 3\% 
da área da bacia. Uso indicado para lavoura com práticas conservacionistas simples.

3(ab)- aptidão restrita nos níveis de manejo $A$ e $B$, solos com mediana a boas reservas de nutrientes, relevo plano, textura argilosa, sujeitos a inundações de curta duração, corresponde a 3\% da área da bacia. Uso indicado para lavoura de ciclos curtos se utilizado maquinário agrícola.

PN7-8- aptidão restrita, solos característicos por sofrer inundação e elevação do lençol freático, solos hidromórficos e planossolos com textura média e argilosa, indicado para pastagem natural, corresponde a 14\% da área.

4p- aptidão regular, áreas com solos com baixa ou medianas reservas de nutrientes, rasos ou pouco profundos, relevo variando de plano, suave ondulado a ondulado, textura média cascalhenta, ocupa $21 \%$ da área. Uso indicado para pastagem plantada.

6- Aptidão desaconselhável, solos rasos, relevo fortemente ondulado, escarpado, desaconselhável ao uso agropecuário. Uso indicado para preservação de fauna e flora. Essa é a classe que ocupa a maior área da bacia do rio Salobra $36 \%$.

Tabela 5: Classes de aptidão agrícola na Bacia Hidrográfica do Rio Salobra-MS (Base cartográfica: Atlas Multirreferencial do Estado do Mato Grosso do Sul).

\begin{tabular}{l|l|c|c}
\hline NOMENCLATURA & \multicolumn{1}{|c|}{ APTIDÃO AGRICOLA } & ÁREA EM KM & ÁREA EM \% \\
\hline 1 Abc & aptidão boa nos níveis ABC & 533,21 & 23 \\
\hline $2 \mathrm{abc}$ & aptidão regular nos níveis abc & 74,79 & 3 \\
\hline $3(\mathrm{ab})$ & $\begin{array}{l}\text { aptidão restrita nos níveis de } \\
\text { manejo a e b }\end{array}$ & 60,29 & 3 \\
\hline $4 \mathrm{p}$ & aptidão regular & 500,29 & 21 \\
\hline PN7-8 & aptidão restrita & 322,65 & 14 \\
\hline 6 & aptidão desaconselhável & 842,51 & 36 \\
\hline
\end{tabular}

\section{O CICLO DE APROPRIAÇÃO DA NATUREZA: transformação da natureza em recurso.}

O processo de ocupação das terras da Serra da Bodoquena por assentamentos rurais e indústrias de exploração mineral para produção de cimento, ganhou maior força a partir de meados da década de 1980 (ALMEIDA, 
2005). Acontecimentos esses que podem ser atribuídos à uma nova configuração da dinâmica socioeconômica e ambiental na área abordada.

A implantação de fazendas de criação gado, assentamentos rurais em algumas porções da bacia do rio Salobra ocorreu sem estudos ambientais prévios, que resultou na ocupação de áreas impróprias para o desenvolvimento de atividades agrícolas, observando-se que a pecuária extensiva se configura como a principal atividade econômica na área (ALMEIDA, 2005).

A pecuária extensiva se caracteriza pela criação de gado solto em extensas áreas de pastagens, exigindo-se assim, maiores áreas desmatadas. Essa atividade normalmente não apresenta qualquer tipo de barreira ao pisoteio do gado, que atinge as margens dos rios e vertentes acentuadas, o que pode ser considerado um fator potencializador da intensificação dos processos erosivos.

$\mathrm{Na}$ perspectiva da relação do processo de ocupação da terra com os problemas ambientais ocasionados por esse processo, remete-se ao processo de apropriação da natureza que inicia-se por sua transformação com emprego da técnica objetivando a produção, que ocorre de acordo com as imposições socioeconômicas das sociedades.

Entende-se por produção a criação meramente humana, que resulta em valor de troca e sua expressão monetária, do qual todos dependiam pra sobreviver, assim a economia é a dependência que a subsistência concreta do homem tem o valor abstrato (ROBERT, 2000).

Nesse sentido, a natureza sem dúvida passa a ter um significado além da esfera ambiental, assumindo uma conotação socioeconômica, por ser influenciado pelas ações sociais, e estas são impulsionadas por fatores econômicos (figura 3).

O ciclo de apropriação da natureza (figura 3) representa as influências que os fatores econômicos impõem às sociedades por meio de suas intencionalidades. Defini-se então como intencionalidade inicial, as intencionalidades cujos objetivos principais são a produção e o lucro. Assim, a atuação direta na natureza por meio do processo de apropriação pode desencadear a superexploração dos recursos e dependerá da intensidade da atuação antrópica sobre a natureza. 


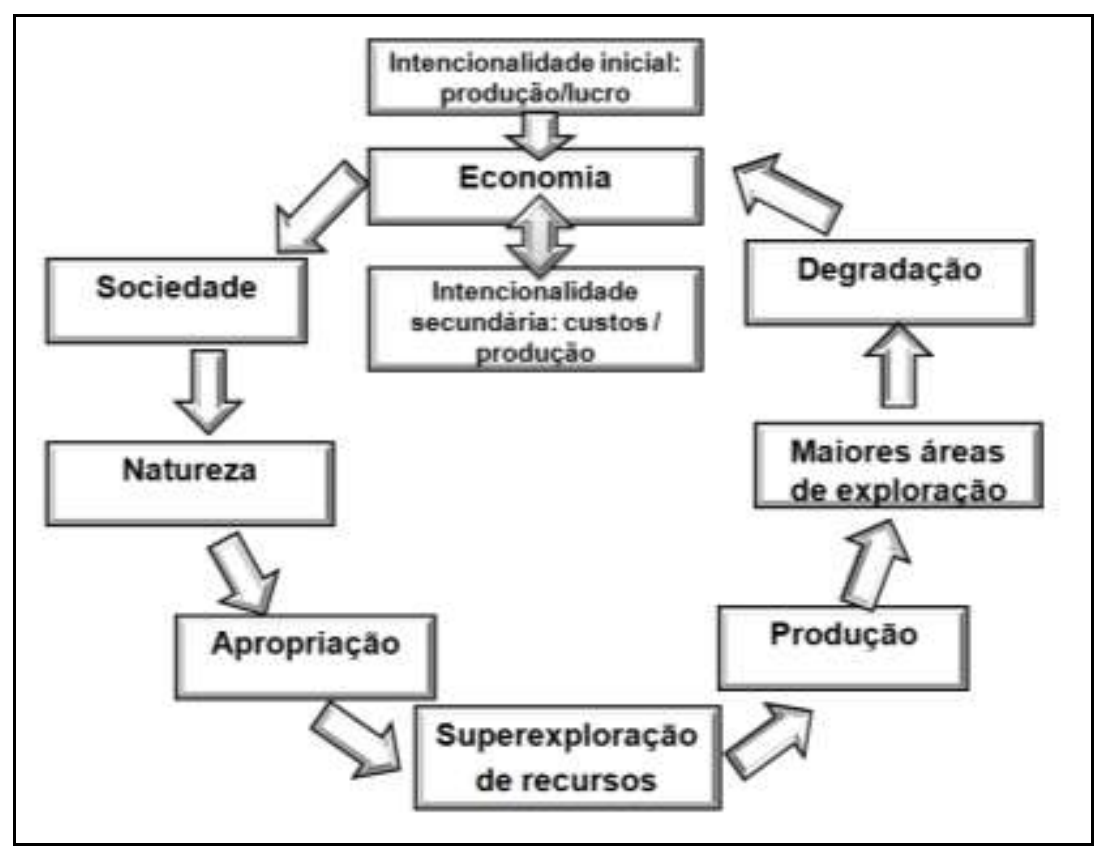

Figura 3- Organograma do ciclo de apropriação da natureza.

À medida em que se aumenta produção, exigem-se maiores áreas para serem exploradas e, muitas vezes pode ocorrer a degradação de ambientes vulneráveis e consequentemente o abandono de áreas como problemas ambientais representativos.

Conforme a condição que a economia é produtiva, a perda de valor ocasiona uma degradação que atinge tudo e todos os que estão envolvidos pelo modo de produção, assim a sociedade e tudo o que se relaciona a ela (ROBERT, 2000).

Desse modo, o ciclo de apropriação da natureza retorna ao fator econômico, mas dessa vez com consequências e efeitos do processo de superexploração da natureza, que exigirá na melhor das hipóteses custos elevado por anos até que as áreas degradadas sejam recuperadas, evidentemente determina-se repouso dessas áreas no período de recuperação, o que pode ocasionar o problema de abandono dessas áreas, no qual a natureza por si não conseguiria recuperar o que foi degradado pelo homem, pois sua capacidade de resiliência ${ }^{3}$ estaria comprometida.

\footnotetext{
${ }^{3}$ Resiliência é definida como a capacidade de um sistema de retornar ás suas condições originais após ser afetado por distúrbios externos. A resiliência é percebida quando sob o efeito das perturbações aleatórias, o sistema, reage por aumento da complexidade e continua a funcionar, elevando seus níveis de entropia buscando se auto-organizar (CAMARGO, 2008).
} 
Todo modo de produção e toda formação econômica e social estabelecem conexões com a natureza por meio dos objetos e meios "naturais" de trabalho dos processos produtivos que daí se desenvolve (LEFF, 2002).

Segundo Leff (2002) a natureza aparece como os objetos de trabalho e os potenciais da natureza que se integram ao processo global de produção capitalista e, em geral, os processos produtivos de toda formação social, como um efeito do processo de reprodução/transformação social.

Shiva (2000) considerou que a relação com a natureza é subordinada à maximização do lucro e da acumulação do capital:

Na economia de mercado o princípio organizador do
relacionamento com a natureza é a maximização do lucro e da
acumulação do capital. A natureza e as necessidades humanas
são gerenciadas através dos mecanismos do mercado. A
ideologia do desenvolvimento é em grande parte baseada na
idéia de trazer todos os produtos da natureza para a economia
de mercado como matéria-prima para produção de
mercadorias. (SHIVA, 2000, p. 315).

O ciclo de apropriação da natureza ao retornar ao fator econômico desencadeará a denominada intencionalidade secundária, por necessitar de mudanças de objetivos para que o processo de apropriação da natureza continue seu ciclo. Assim, a recuperação das áreas degradadas para que o processo produtivo continue sua eficiência, seria a alternativa mais coerente para essa área.

Robert (2000) considerou que os efeitos negativos oriundos da produção são denominados contra-produtiva, não importando o quanto modernas sejam as técnicas utilizadas na apropriação, se não considerar os limitantes físicos naturais, os efeitos da produção tenderá a atingir metas opostas dos objetivos iniciais.

Assim:

$\mathrm{Na}$ medida em que são danificados os limites que possibilitam à natureza renovar-se, e que lhe dão a capacidade de "ressurgir", gera-se, então, a verdadeira escassez - as florestas desaparecem, os rios secam, os solos perdem sua fertilidade, água, a terra e o ar são poluídos. (SHIVA, 2000, p.308).

Robert (2000) considerou que a produção econômica demanda como condição necessária, uma idéia de degradação irreversível, resultado de um processo historicamente identificável, desse modo, o feedback que torna 
possível a produção da natureza por meio da sua apropriação é também o ponto de origem dos problemas ambientais contemporâneos, como inundações, assoreamento, erosão, poluição.

Desse modo, a apropriação da natureza, não se considerando seus limitantes físico-naturais, pode desencadear processos irreversíveis, no qual a urgência da produção econômica em tornar qualquer área explorável e, aumentar os níveis de produção, exige da natureza uma capacidade além do que se entende por natural para que consiga retornar as suas características originais.

Conforme essas premissas enfatiza-se a importância do uso adequado da terra, obedecendo as características físico-naturais da paisagem onde os recursos ambientais como solo estão inseridos.

\section{PROCEDIMENTOS METODOLÓGICOS}

A metodologia utilizada na presente pesquisa está baseada na Ecodinâmica proposta por Tricart (1977) e na metodologia de Zoneamento Ecológico Econômico, proposta por Crepani et al. (2008).

A Ecodinâmica propõe uma relação de variáveis da paisagem objetivando definir unidades morfodinâmicas em Meios Estáveis, Meios Intergrades e Meios Instáveis.

Desse modo foi organizada uma caracterização dos Planos de Informações, que contou com consulta em material como projeto RADAMBRASIL, Mapa geológico do Estado do Mato Grosso do Sul, Atlas Multi- referencial do Estado de Mato Grosso do Sul, PCBAP (Plano de Conservação da Bacia do Alto Paraguai) e constatações a campo.

Foram realizados trabalhos de campo para averiguação das formações geológicas, das morfologias de relevos, dos tipos de solos, dos usos e ocupações da terra encontrada na área estudada, confirmando as interpretações das imagens de satélite.

O passo seguinte consistiu em organizar e editar as bases cartográficas de geologia e solos. Essas informações foram compiladas em ambiente de SIG, com o software SPRING. 
Foram produzidos os mapas de intensidade pluviométrica a partir de dados das estações pluviométricas, o mapa de vulnerabilidade do relevo, com base nas informações dos dados SRTM. Para elaboração dos mapas de uso da terra e cobertura vegetal utilizou-se imagens de satélite Landsat 5 TM, após elaboração do banco de dados foram gerados os mapas sínteses de vulnerabilidade à perda de solos de indicação de uso da terra.

Foram abordadas as seguintes variáveis da bacia hidrográfica para elaboração do mapa de vulnerabilidade das paisagens à perda de solos (Figura 4):

Vulnerabilidade dos Solos (Níveis de erodibilidade dos solos, Fonte: Projeto RadamBrasil , Embrapa 1999);

Vulnerabilidade da Intensidade Pluviométrica (dados de intensidade pluviométrica mm/ mês; Fonte: hidroweb, dez estações na região);

Vulnerabilidade do relevo (cruzamento dos P.I. Declividade + amplitude altimétrica);

Vulnerabilidade Geológica (Grau de coesão das rochas que compõe cada unidade geológica; Projeto RadamBrasil, Mapa Geológico do Mato Grosso do Sul (2006);

Vulnerabilidade Cobertura Vegetal e Uso da terra (Fonte: Imagens Landsat 5 TM).

O mapeamento da vulnerabilidade à perda de solo foi elaborado em ambiente de Sistema de Informações Geográficas (SIG), onde se utilizou o software SPRING, que permitiu o armazenamento das informações, tratamento de dados e correlações da variáveis, resultando assim no mapa síntese de vulnerabilidade da paisagem à perda de solos. O mapa síntese resultou da correlação dos Planos de Informações, contendo variáveis da paisagem (figura $5)$. 


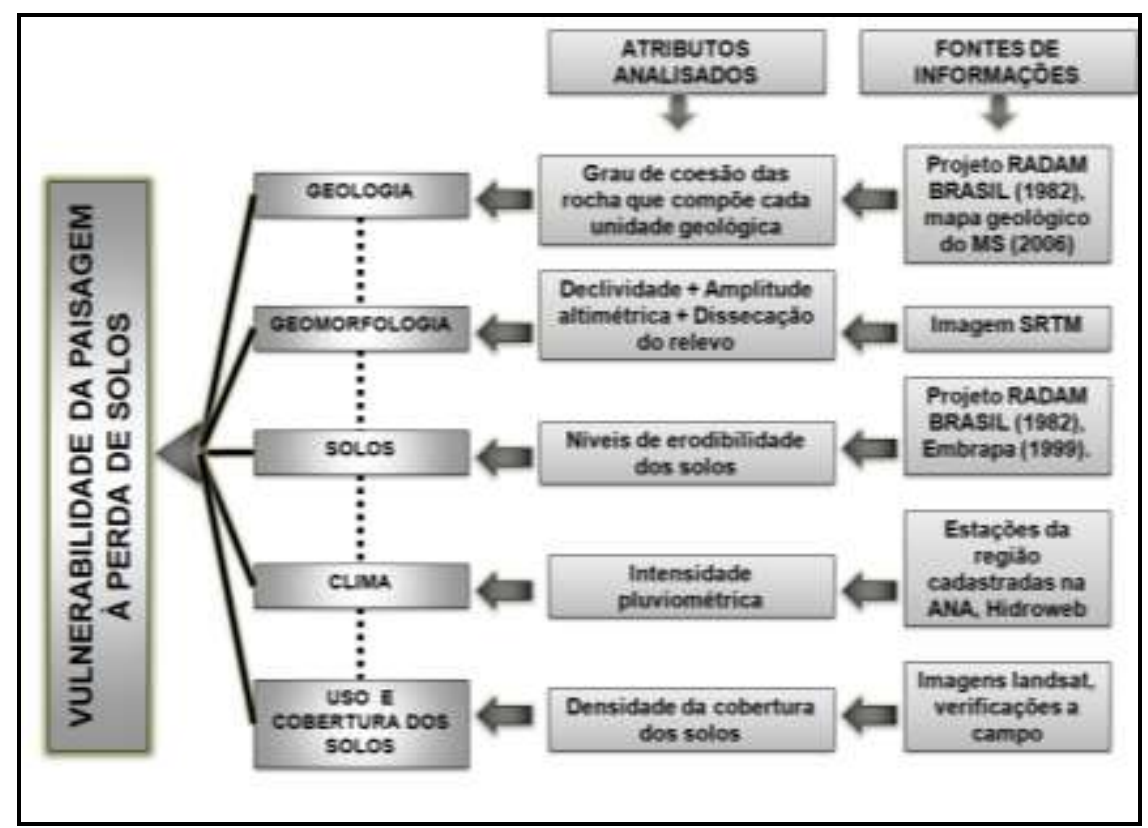

Figura 4: Organograma para elaboração da vulnerabilidade da paisagem à perda de solos (Elaborado pelo autor).

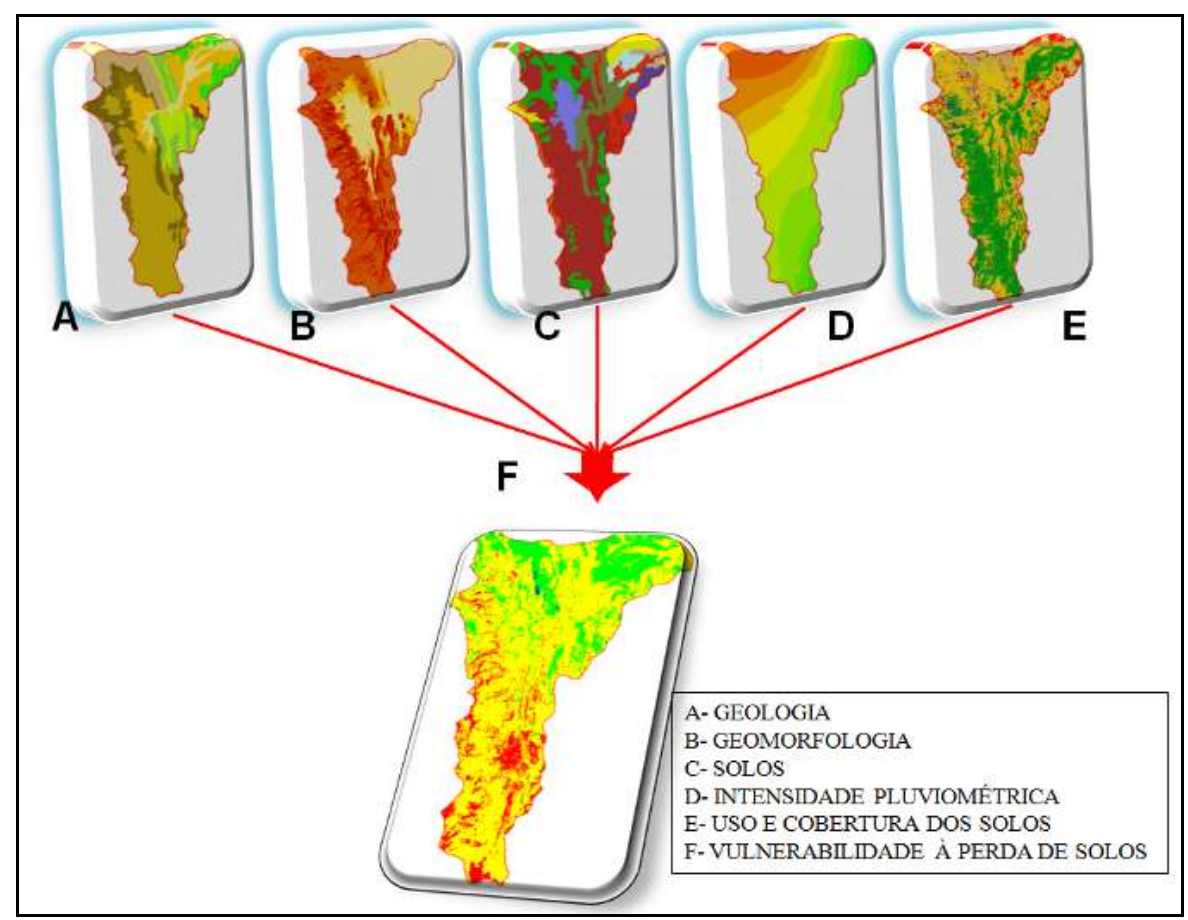

Figura 5: Esquema metodológico da correlação de P.I.s para elaboração do mapa de vulnerabilidade à perda de solos (Elaborado pelo autor).

O mapa síntese de vulnerabilidade da paisagem à perda de solos da Bacia Hidrográfica do Rio Salobra é uma informação produzida a partir da análise espacial em Sistema de Informações Geográfica, tendo como apoio o 
Suporte de Decisão AHP (Processo Analítico Hierárquico) que se caracteriza como uma ferramenta de suporte à decisão, que permite organizar e estabelecer um modelo racional da correlação de variáveis (CÂMARA, et al., 1996).

Desse modo, as variáveis geologia, geomorfologia, solos, intensidade pluviométrica e uso da terra e cobertura vegetal, foram selecionadas no módulo de Análise Espacial do SPRING, como critério de análise, estabelecendo-se o mesmo peso para cada variável, conforme a metodologia Crepani et al.(2001).

O resultado do procedimento de implementação da AHP, após se calcular o peso dos critérios, gerou-se uma base de programação em LEGAL ${ }^{4}$ (Linguagem Espacial para Geoprocessamento Algébrico), em formato nativo do SPRING, editado posteriormente em arquivo comum de bloco de notas.

$\mathrm{O}$ arquivo com a base de programação completou-se com as informações específicas, na qual foram atribuídos os valores de 0 a 1 , sobre os dados nos quais se deseja aplicar o procedimento e, em seguida a programação editada foi copiada no editor de modelos de Álgebra do programa em LEGAL.

Antes de executar a operação deve-se criar no modelo de dados do SPRING, uma categoria saída em Modelo Numérico do Terreno (MNT), para receber a imagem gerada após execução da operação. A imagem MNT gerada após a execução da operação utiliza o interpolador de média ponderada.

O procedimento final para geração do mapa de vulnerabilidade da paisagem à perda de solos é o fatiamento da imagem que pode ser definido como um procedimento que irá transformar uma categoria MNT de entrada, em uma categoria Temática de saída, estabelecendo assim as classes temáticas de acordo com a grade gerada em LEGAL (Figura 6).

\footnotetext{
${ }^{4}$ Segundo Câmara et al. (1996) um programa em LEGAL consiste de uma sequência de operações descritas por sentenças construídas segundo regras gramaticais envolvendo operadores, funções e dados representados em Planos de Informações de um mesmo projeto existente de um banco de dados SPRING. O Programa em LEGAL é definido como uma ferramenta que possibilita a realização de análises espaciais através de álgebra de mapas.
} 


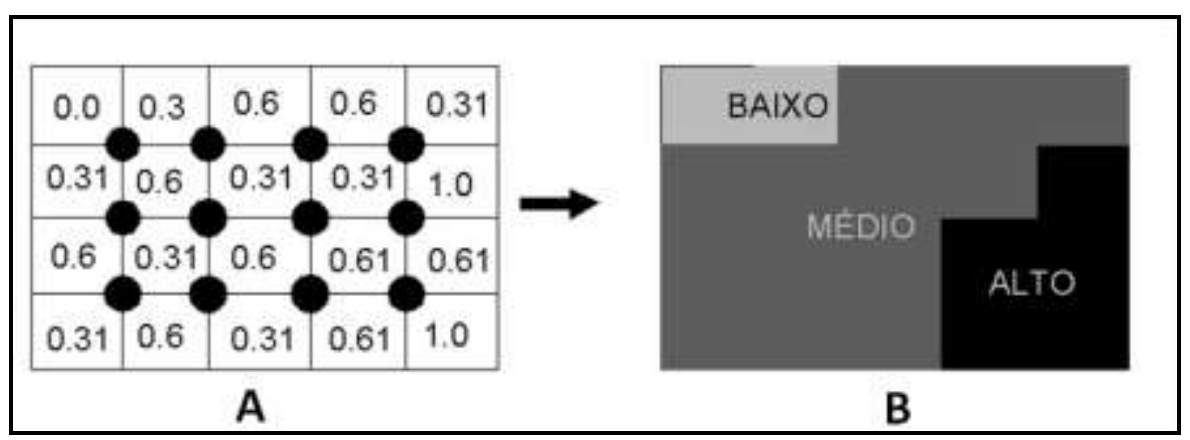

Figura 6- Exemplo de fatiamento de imagem em MNT gerada a partir da AHP, (B) categoria temática pós-fatiamento (Adaptado de Câmara et al. 1996).

A indicação para uso da terra foi estabelecida a partir da correlação dos Planos de Informações de Vulnerabilidade à perda de solos, Aptidão Agrícola e Áreas de Preservação Permanente (Figura 7).

O mapa de Aptidão Agrícola foi organizado utilizando-se a base cartográfica do Atlas Multireferêncial do Estado de Mato Grosso do Sul (1990) editado em ambiente de SIG, no Software SPRING o que permitiu a correlação com os outros P.I.'s.

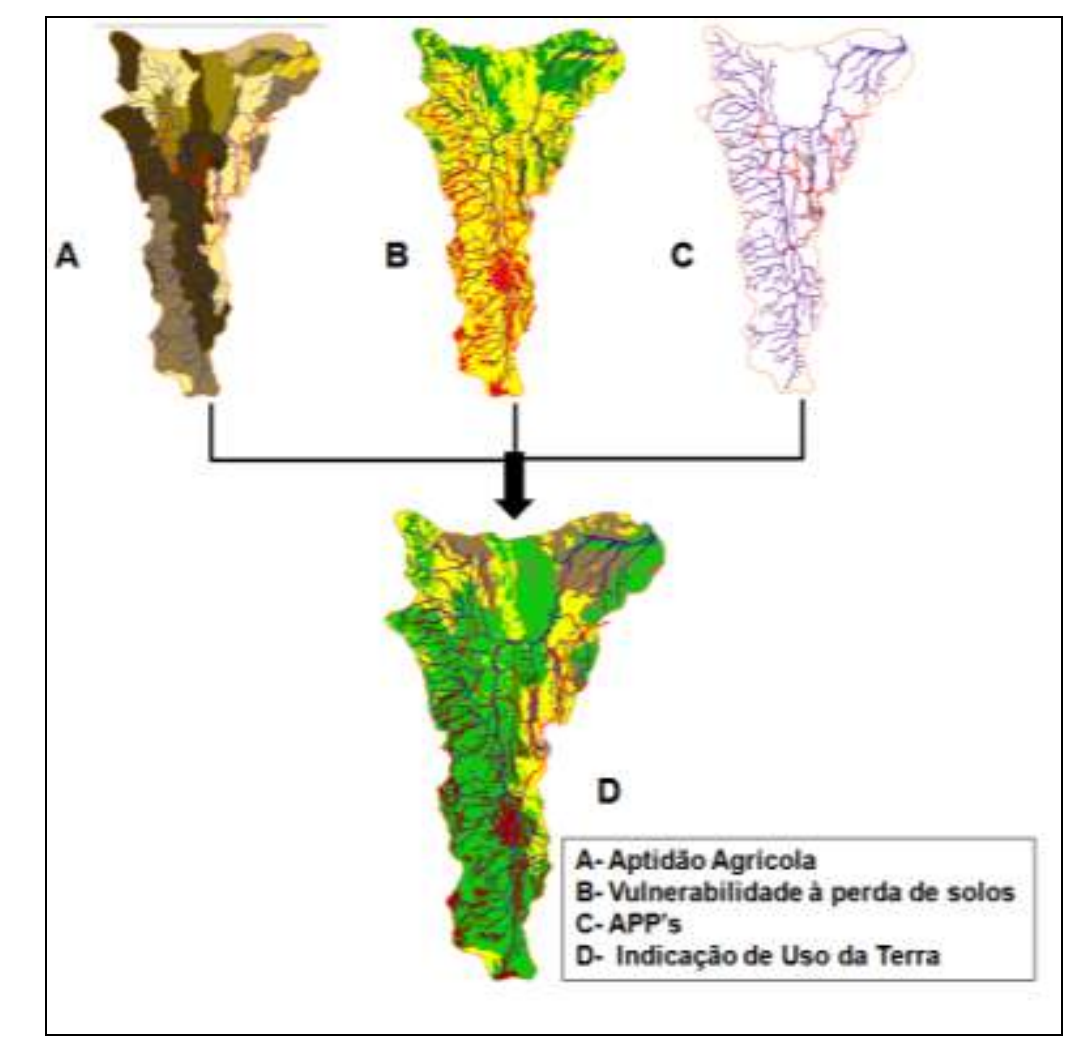

Figura 7- Correlação dos Planos de Informações para definição do mapa de indicação de uso da terra (Elaborado pelo autor). 
O mapa síntese de Indicação de uso da terra na bacia hidrográfica do rio Salobra foi produzido seguindo os mesmos procedimentos operacionais utilizados para elaboração dos mapas de Vulnerabilidade à perda de solos, no qual também implementou-se a análise espacial em Sistema de Informações Geográficas, utilizando-se o Suporte de Decisão AHP (Processo Analítico Hierárquico).

Posteriormente à etapa de implementação da AHP, calculou-se o peso dos critérios, gerando a base de programação em LEGAL (Linguagem Espacial para Geoprocessamento Algébrico).

O processamento da programação em LEGAL resultou em uma modelo em MNT que, após o procedimento de fatiamento para se estabelecer as classes de do mapa temático, resultou no mapa síntese de indicação de uso da terra.

\section{RESULTADOS}

A indicação para uso da terra definiu-se a partir de condicionantes físiconaturais, ressaltando as atividades antrópicas e suas correlações com as variáveis de vulnerabilidade à perda de solos como: uso da terra e cobertura vegetal, intensidade pluviométrica, geologia, relevo e tipos de solos, combinadas às classes de Aptidão Agrícola e as Áreas de Preservação Permanente.

Desse modo, cinco classes de indicação do uso da terra foram definidas:

CLASSE I: caracterizam-se por apresentar relevo plano, rochas densas, composta principalmente por rochas que apresentam resistência à erosão, como as Graníticas e Gnaises, e solos profundos e bem desenvolvidos como os Nitossolos (Figura 8). 


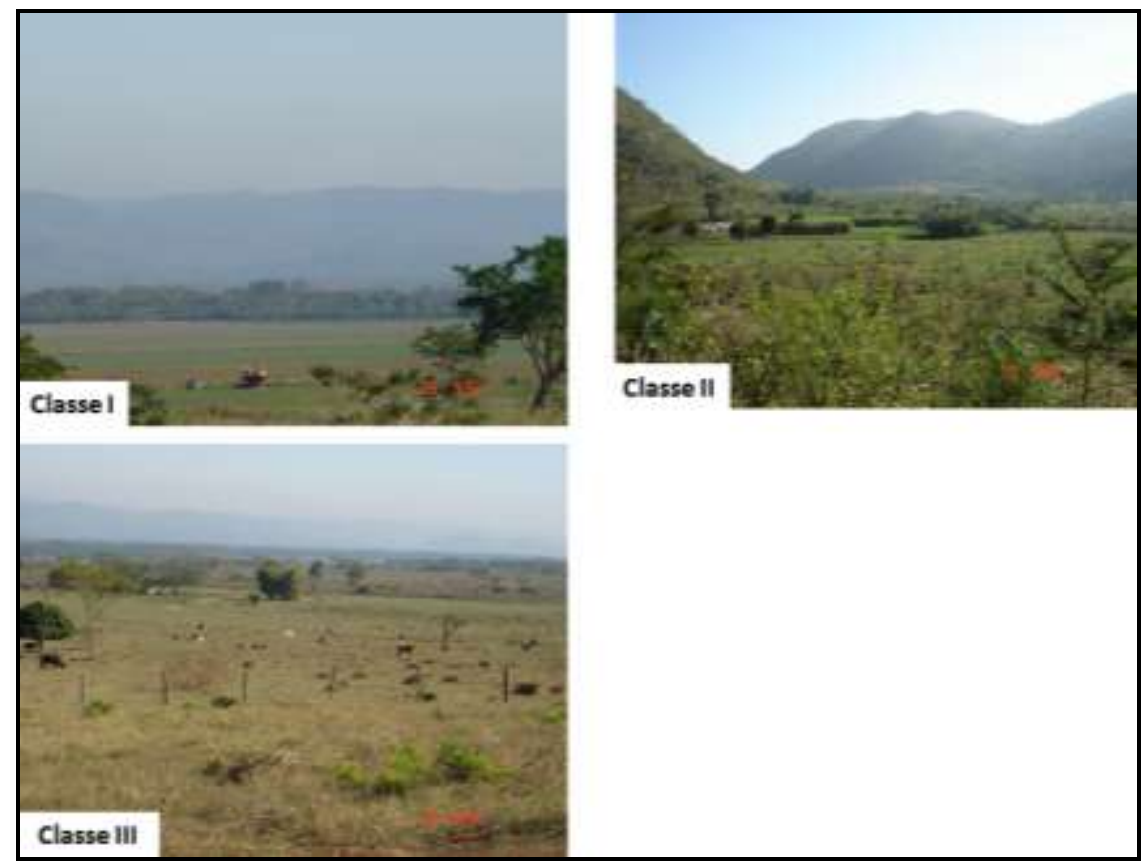

Figura 8: Fotografia exemplificando as Classes I, II, III de uso da terra na Bacia Hidrográfica do Rio Salobra. (Fonte: autor)

São áreas que apresentam aptidão boa ou regular, caracterizam-se por apresentar solos com boas reservas de nutrientes, quanto á vulnerabilidade à perda de solos enquadra-se nas classes Estável/ Moderado Estável, essa classe de uso da terra pode suportar práticas agrícolas com utilização de mecanização, e outros implementos agrícolas. Essa classe é indicada para lavouras de ciclo longo/anuais, mas, não representou $1 \%$ da área estudada (Figura 9).

CLASSE II: são áreas que apresentam aptidão boa ou regular, caracterizam-se por apresentar solos com boas ou medianas reservas de nutrientes como os Chernossolos Argilúvicos, quanto à vulnerabilidade à perda de solos enquadra-se nas classes Estável/Moderado Estável. Essa classe de uso da terra é indicada para agricultura, com lavouras de ciclos curtos/ sazonais, sobretudo sem artifício de mecanização ou com utilização apenas de 
implementos agrícolas simples (Figura 8), essa classe corresponde a $16 \%$ da área da bacia hidrográfica (Figura 9).

CLASSE III: essa classe corresponde às áreas que apresentam aptidão regular, são áreas com solos com baixas ou medianas reservas de nutrientes, rasos ou pouco profundos, que se associam à áreas de vulnerabilidade medianas, essas áreas são inaptas para lavouras, mas indicada para uso com pastagem em áreas com relevo plano ou suave ondulado. Esta classe é verificada em $20 \%$ da área (Figura 9).

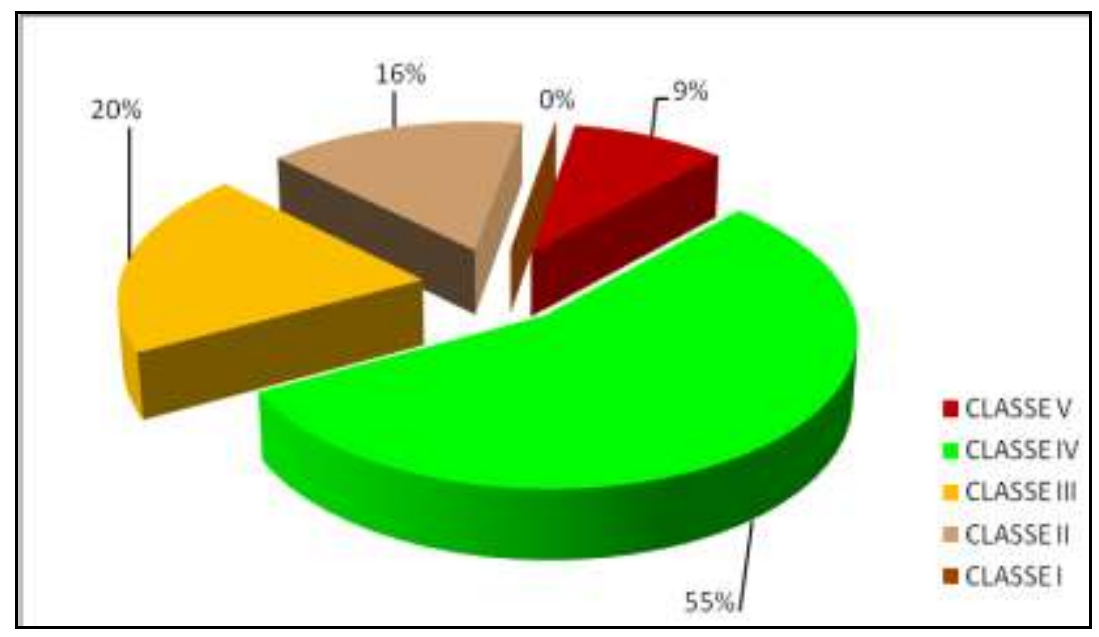

Figura 9: Indicação de Uso da terra na bacia hidrográfica do Rio Salobra-MS (Elaborado pelo autor).

CLASSE IV: são áreas que ainda apresentam características de paisagens preservadas com áreas de floresta, mas está associada às áreas vulneráveis e moderado vulnerável associadas com aptidão agrícola restrita ou inapta (Figura 10).

A principal indicação para essas áreas é a preservação, porém, desde que não ocorra em declividades incompatíveis (>20\%) pode ser ocupada por reflorestamento ou pastagem, porém, no caso do uso por pastagem necessitase de medidas conservacionistas criteriosas. Essa classe engloba também as Áreas de Preservação Permanente estabelecidas pela Legislação Ambiental vigente. Essa classe é verificada em $55 \%$ da área total estudada. 
CLASSE V: Essa classe é caracteriza-se por apresentar correlação do relevo ondulado á fortemente dissecado, rochas pouco densas, solos rasos como os Chernossolos Rêndzicos.

Essa classe compreende as áreas que apresentam grau de vulnerabilidade muito alto e associa-se às áreas sem aptidão para usos agrícolas, caracterizam-se ainda por apresentar uso intenso da terra, como solo exposto ou com usos agrícolas.

Corresponde às áreas que apresentam problemas de conservação dos solos, esta classe é indicada para recuperação prioritária e, ocupam 9\% da área total da Bacia Hidrográfica do Rio Salobra (Figura 10).

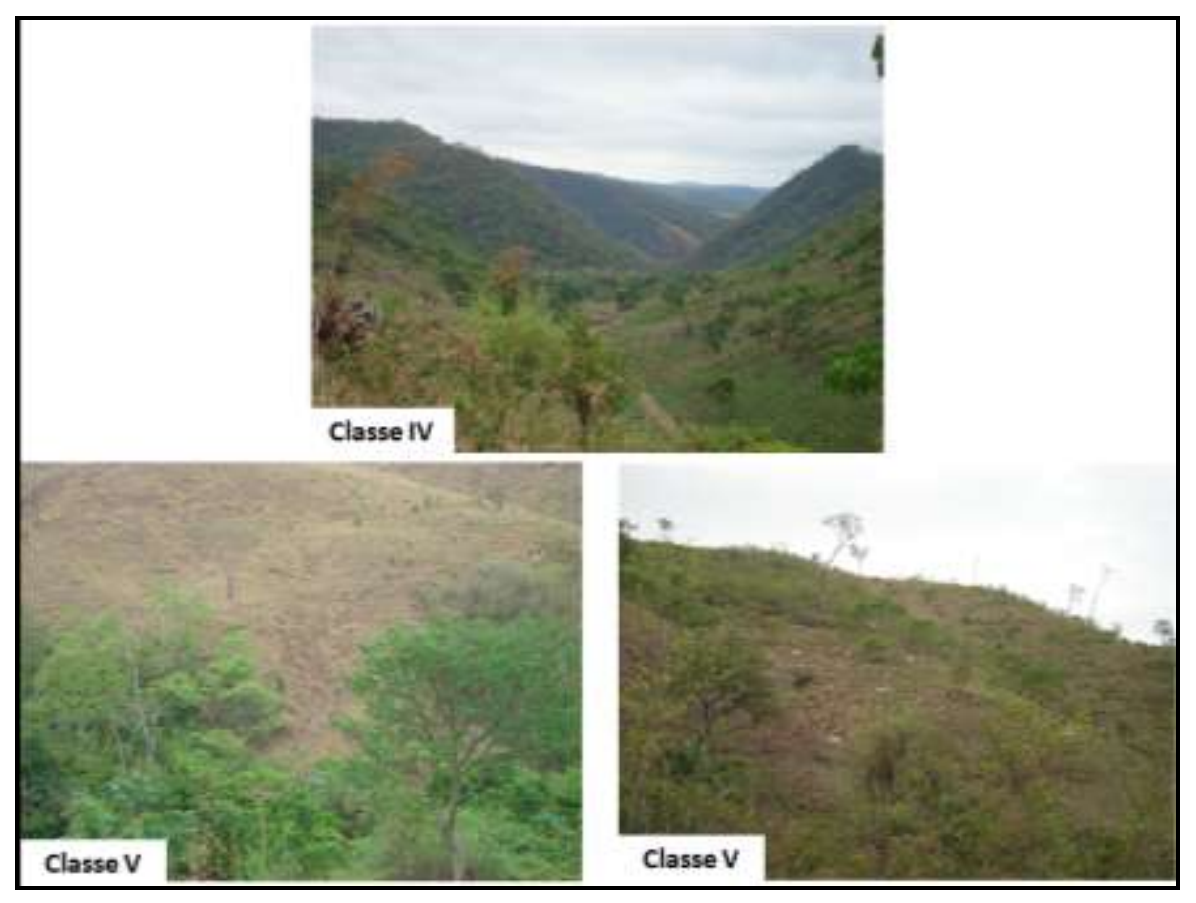

Figura 10: Fotografia exemplificando as Classes I, II, III de uso da terra na Bacia Hidrográfica do Rio Salobra. (Fonte: autor). 


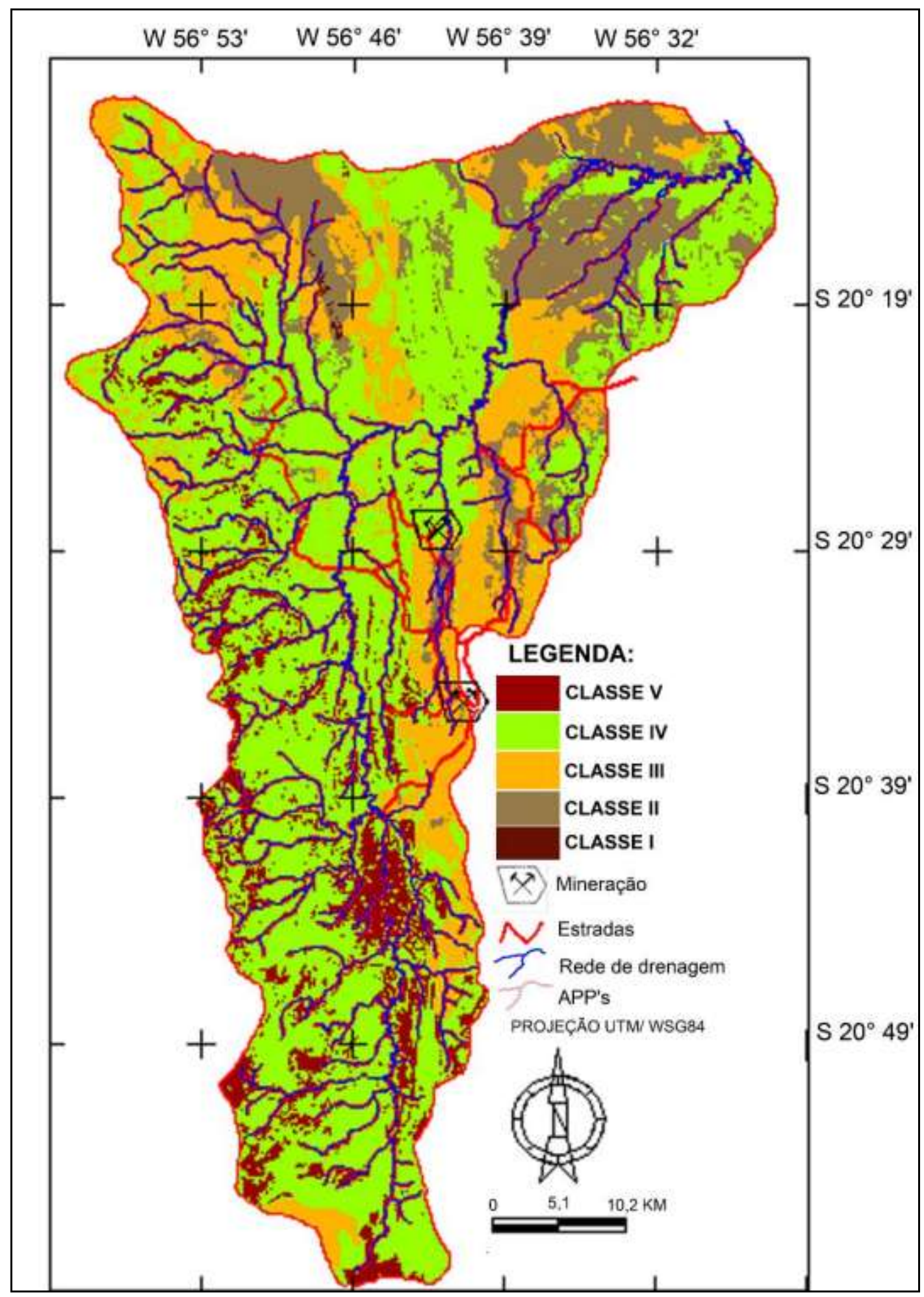

Figura 11: Mapa de Indicação de Uso da terra na Bacia Hidrográfica do Rio Salobra-MS (Elaborado pelo autor). 


\section{CONSIDERAÇÕES FINAIS}

A partir das informações correlacionadas foram definidas as áreas de indicação para uso da terra, conforme a atual conjuntura da paisagem da Bacia Hidrográfica do Rio Salobra, que é resultado das diversas inter-relações com o uso da terra, que associado à outras variáveis podem comprometer em diferentes níveis a dinâmicas de processos na bacia hidrográfica, no qual ressalta-se os processos erosivos que apresenta uma relação direta com a cobertura vegetal e, sua retirada para fins de práticas agropecuárias torna mais intenso esses processos.

Conforme os resultados apresentados, verificou-se que a maior porção da Bacia Hidrográfica do Rio Salobra, 64\% da área, apresentaram indicação restritiva quanto ao uso da terra, por caracterizar-se como um ambiente vulnerável e com aptidão restrita ou inapta para usos agrícolas. Esses dados sugerem outro fator importante, que seria o comprometimento ambiental causado pelos usos inadequados da terra, como a intensificação dos processos erosivos e consequentemente a perda de terras produtivas.

O principal problema ao se tratar do uso da terra são as áreas de incompatibilidade do uso, que correspondem às áreas utilizadas de maneira inadequada, para fins de pecuária extensiva e atividades agrícolas, em que não são respeitadas as limitações físico-naturais de ambientes vulneráveis, como exemplo, áreas com relevo fortemente dissecado ou áreas de solos rasos suscetíveis à erosão.

Esse cenário é visualizado de modo cada vez mais frequente, visto que, historicamente na Região da Serra da Bodoquena, vem sendo imposto um processo de apropriação da natureza, no qual a partir da implantação de fazendas de criação gado, assentamentos rurais em algumas porções da bacia resultaram na ocupação de áreas impróprias para o desenvolvimento de atividades agropecuárias.

Nesse processo de apropriação, a natureza é concebida apenas como uma mercadoria, logo, passível de uma superexploração, de forma inconsequente e sem planejamento adequado. 
Por fim, ressalta-se a necessidade de estudos aprofundados na área que visem propor diretrizes para o ordenamento do território, visto que há uma carência de estudos, dados e bases cartográficas em escala adequada, que possibilite encaminhamentos na perspectiva da atuação de políticas de uso e ocupação da área.

\section{REFERÊNCIAS BIBLIOGRÁFICAS}

ALMEIDA, Márcia Ajala. Política de desenvolvimento e estruturação do espaço regional da área da Bodoquena em Mato Grosso do Sul. Tese de Doutorado apresentada ao Programa de Pós-graduação em GeografiaUniversidade Estadual Paulista - UNESP - Faculdade de Ciências e Tecnologia, Campus de Presidente Prudente, 2005.

BERTONI, José \& LOMBARDI NETO, Francisco, Conservação do solo, São Paulo: Ícone, 4를. 1999.

CAMARA G., SOUZA R.C.M., FREITAS U.M., GARRIDO J; "SPRING: Integrating remote sensing and GIS by object-oriented data modelling"; Computers \& Graphics, 20: (3) 395-403, May-Jun 1996.

CAMARGO, Luís Henrique Ramos de, A ruptura do meio ambiente: conhecendo as mudanças ambientais do planeta através de uma nova concepção da ciência: a geografia da complexidade, Rio de Janeiro: Bertrand Brasil, 2ª Ed. 2008.

CREPANI, Edison. et al., Sensoriamento remoto e geoprocessamento Aplicados ao Zoneamento Ecológico-Econômico e ao Ordenamento Territorial. São José dos Campos, INPE-8454-RPQ/722. 2001.

CREPANI, Edison. et al.; Intensidade Pluviométrica: uma maneira de tratar dados pluviométricos para análise da vulnerabilidade de paisagens à perda de solo; São José dos Campos, INPE -11237-RPQ/760. 2004.

CREPANI, Edison et al., Zoneamento Ecológico-econômico; In: FLORENZANO, Teresa G; Geomorfologia: Conceitos e tecnologias atuais. São Paulo, Oficina de Textos, 2008. Cap.10, p. 285-314.

EMBRAPA - Empresa Brasileira de Pesquisa Agropecuária. Centro Nacional de Pesquisa de Solos. Sistema brasileiro de classificação dos solos. Brasília, 1999.

ESTADO DO MATO GROSSO DO SUL, GEOPARK BODOQUENAPANTANAL: Dossiê de candidatura à Rede Global de Geoparks Nacionais sob auspício da Organização das Nações Unidas para Educação, Ciências e Cultura/UNESCO. Companhia de Pesquisa de Recursos Minerais - Serviço Geológico do Brasil, 2010. 
HIDROWEB- Sistema de Informações Hidrológicas, Série histórica de dados de pluviométricos (on-line); site <http://hidroweb.ana.gov.br/>; acessado em 12 de janeiro de 2011.

INSTITUTO NACIONAL DE PESQUISAS ESPACIAIS (INPE): Catálogo de Imagens LANDSAT; <http://www.dgi.inpe.br/>, acessado em 03 de feveiro de 2011.

LEFF, Enrique; Epistemologia Ambiental; São Paulo: Editora Cortez, $3^{\circ}$ Ed., 2002.

LEPSCH, Igor F. Formação e Conservação dos solos. São Paulo: Oficina de Textos, 2002.

MARTINS, J. de O. (Coordenador Geral). Atlas Multirreferêncial do Estado de Mato Grosso do Sul. Campo Grande, MS. SEPLAN/IBGE, 1990.

MINISTÉRIO DE MINAS E ENERGIA, SECRETARIA DE GEOLOGIA, MINERAÇÃO E TRANSFORMAÇÃO MINERAL. CPRM, Geologia e Recursos Minerais do Estado de Mato Grosso do Sul, Serviço Geológico do Brasil, Campo Grande - MS, 2006.

MINISTÉRIO DE MINAS E ENERGIA: SECRETARIA - GERAL, PROJETO RADAM BRASIL, Levantamento de Recursos Naturais, Vol.28, Folha SF. 21 CAMPO GRANDE, Rio de Janeiro. 1982.

MINISTÉRIO DO MEIO AMBIENTE, DOS RECURSOS HÍDRICOS E DA AMAZÔNIA LEGAL, Plano de Conservação da Bacia do Alto ParaguaiPCBAP. Volumes: I e II, Tomos I e II, Programa Nacional de Meio Ambiente, 1997.

SÁNCHES, Roberto O; Zoneamento Agroecológico: Bases para o ordenamento ecológico-Paisagístico do meio rural e florestal. Cuiabá MT, Fundação de Pesquisas Cândido Rondon, 1991.

ROBERT, Jean, Produção; In: In: WOLFGANG, Sachs (editor), Dicionário do desenvolvimento, Tradutores: Vera Lúcia M. Joscelyne, Susana de Gyalokay e Jaime A. Clasen. Petrópolis - RJ, Vozes, 2000.

SHIVA, Vandana, Recursos Naturais; In: WOLFGANG, Sachs (editor), Dicionário do desenvolvimento, Tradutores: Vera Lúcia $M$. Joscelyne, Susana de Gyalokay e Jaime A. Clasen. Petrópolis - RJ, Vozes, 2000.

SILVA NETO, J. C. A. \& NUNES, J. O. R. Vulnerabilidade da paisagem à perda de solos na Bacia Hidrográfica do Rio Salobra-MS. In: Anais do IX Encontro Nacional da Associação de Pós-graduação em Geografia ENANPEGE, Goiânia - GO, 2011.

TRICART, Jean. Ecodinâmica. Rio de Janeiro: IBGE, 1977. 